\title{
Tale of Two Endocrine Organs: Medullary Thyroid Carcinoma (MTC) With Ectopic Cushing Syndrome
}

Naval Bansal $^{1}$, Samir Saini ${ }^{1}$, Mayilvaganan Sabaretnam ${ }^{1}$ and Anjali Mishra ${ }^{1 *}$

${ }^{1}$ Department of Endocrine Surgery, Sanjay Gandhi Postgraduate Institute of Medical Sciences, Raebareli Road, Lucknow, India

\begin{abstract}
Ectopic Cushing syndrome from medullary carcinoma thyroid is a rare entity. Lack of typical Cushing features and rarity of association between the two disease spectrums make diagnosis more challenging. We report a case of a 28 years old woman who showed ectopic ACTH production from medullary carcinoma thyroid. High index of suspicion and curative surgery if feasible should be the aim while managing this rare entity.
\end{abstract}

\section{Keywords: Ectopic cushing syndrome; ACTH}

\section{Introduction}

Cushing syndrome occurs due to excess glucocorticoid exposure with endogenous causes includes cortisol-producing adrenal tumour, excess secretion of adrenocorticotrophic hormone (ACTH) from a pituitary tumour (Cushing's disease); or an ectopic ACTH-producing tumour [1]. Ectopic ACTH production accounts for around $20 \%$ of ACTH-dependent Cushing syndrome and around 10\% of all types of Cushing syndrome [2]. Various tumours can cause ectopic ACTH production, especially those of neuroendocrine cell origin, which are part of amine precursor uptake and decarboxylation (APUD) system [3]. The most common diseases that cause ectopic ACTH syndrome are Endobronchi $\neg$ al carcinoid tumors and Small cell lung cancer and rarely, Medullary carcinoma thyroid (MTC) [4]. MTC is a rare disease with incidence of 3\% amongst all thyroid cancer and out of these approximately $0.6 \%$ of patients suffer from ectopic ACTH syndrome $[5,6]$.

\section{Case Report}

A 28 years old woman presented with goiter of two years duration with rapid progression over preceding four months. She noticed skin and mucosal pigmentation over last one year with difficulty in getting up from squatting position. She also gave history of nocturnal cough, watery diarrhea, oligo-hypomenorrheoa with loss of weight for last 6 months. She was non-diabetic and non-hypertensive. On examination, she was thin built with BMI of $18.1 \mathrm{~kg} / \mathrm{m}^{2}$. She has hyperpigmentation over knuckles (Figure 1), oral mucosa and previous caesarean scar with abdominal striae. She also had a large multinodular goiter involving both lobes of thyroid with retrosternal extension and left lateral cervical lymphadenopathy (Figure 2). She has proximal myopathy with grade 4 power in bilateral lower limbs.

On investigation, She was biochemically Euthyroid with TSH value of $4.85 \mathrm{mIU} / \mathrm{L}$. Fine needle aspiration cytology was suggestive of Medullary carcinoma thyroid with serum calcitonin value more than 20000pg/ml. Contrast-Enhanced Computed Tomography (CECT) neck and thorax revealed, heterogeneously enhancing lesion in left lobe of thyroid with extension in to thorax up to bifurcation of carina with large lymph nodal mass on left side, and multiple sub-pleural nodules. Due to financial constrains and apparently sporadic nature, RET gene mutation analysis was not performed. Overnight Dexamethasone test $(464 \mathrm{nmol} / \mathrm{L})$ and $24 \mathrm{hrs}$ urinary free cortisol $(273 \mathrm{mcg} / 24 \mathrm{Hrs})$ showed endogenous hypercortisolism which was confirmed with Low dose Dexamethasone test $(607 \mathrm{nmol} / \mathrm{L}) .11 \mathrm{pm}$ and 8 am serum ACTH values $72 \mathrm{pg} / \mathrm{ml} \& 78 \mathrm{pg} / \mathrm{ml}$ respectively $(>22 \mathrm{pg} / \mathrm{ml}$ suggests ACTH dependence) along with High dose Dexamethasone test $(601 \mathrm{nmol} / \mathrm{L})$ suggests presence of ectopic source of ACTH. So, with the possibility of ectopic ACTH production from MTC patient underwent total thyroidectomy with central and left modified lateral neck dissection. As left lobe was extending into the posterior mediastinum below the arch of aorta, strenotomy was performed for tumour resection. In postoperative period, patient received stress doses of corticosteroids in view of suppressed Hypothalamic Pituitary Adrenal axis (HPA). Final histopathology was MTC which was positive for calcitonin and ACTH on immunohistochemistry (Figure 3), confirming diagnosis of ectopic ACTH secretion. After three months follow up, there was partial resolution of skin hyperpigmentation, she was cured of diarrhea and menstrual irregularity. Proximal myopathy had improved though HPA was still suppressed and she was still on replacement doses of steroid. ACTH value is $<5 \mathrm{pg} / \mathrm{ml}$ with drop in serum calcitonin value to 4010 $\mathrm{pg} / \mathrm{ml} /$. In literature, $30 \%$ to $80 \%$ of the patients' inspite of curative surgery still show Persistent hypercalcitoneamia and advanced tumor stage is one of the key factor [5,7].

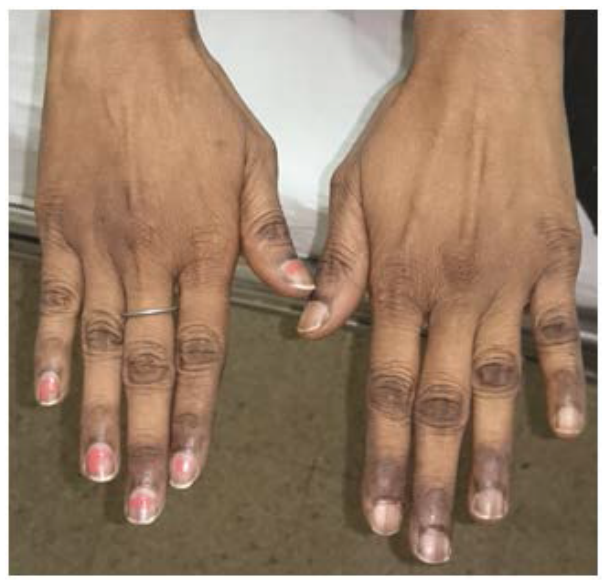

Figure 1: Darkening of knuckles.

*Corresponding author: Mishra A, Additional Professor, Department of Endocrine Surgery, Sanjay Gandhi Postgraduate Institute of Medical Sciences, Raebareli Road, Lucknow, India, Tel: +910-0522- 2668004; Fax: +91-0522- 2668777; E-mail: anjali_mishra2000@yahoo.com

Received December 18, 2014; Accepted February 19, 2015; Published February 27,2015

Citation: Bansal N, Saini S, Sabaretnam M, Mishra A (2015) Tale of Two Endocrine Organs: Medullary Thyroid Carcinoma (MTC) With Ectopic Cushing Syndrome. Surgery Curr Res 5: 217. doi:10.4172/2161-1076.1000217

Copyright: ( 2015 Bansal N, et al. This is an open-access article distributed under the terms of the Creative Commons Attribution License, which permits unrestricted use, distribution, and reproduction in any medium, provided the original author and source are credited. 


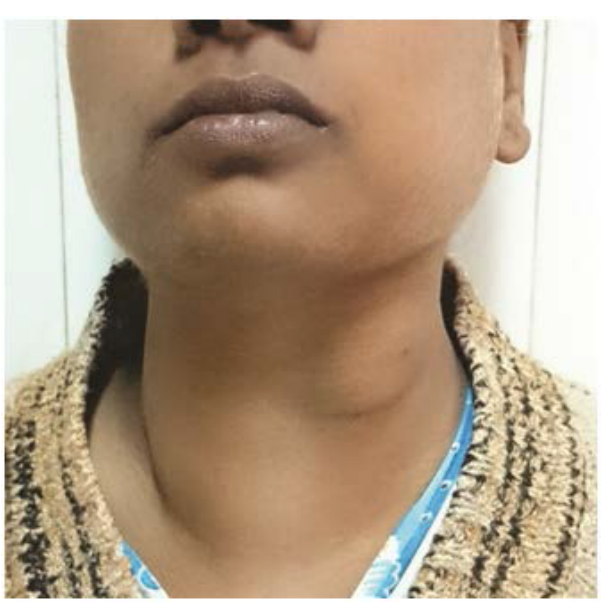

Figure 2: Goiter.

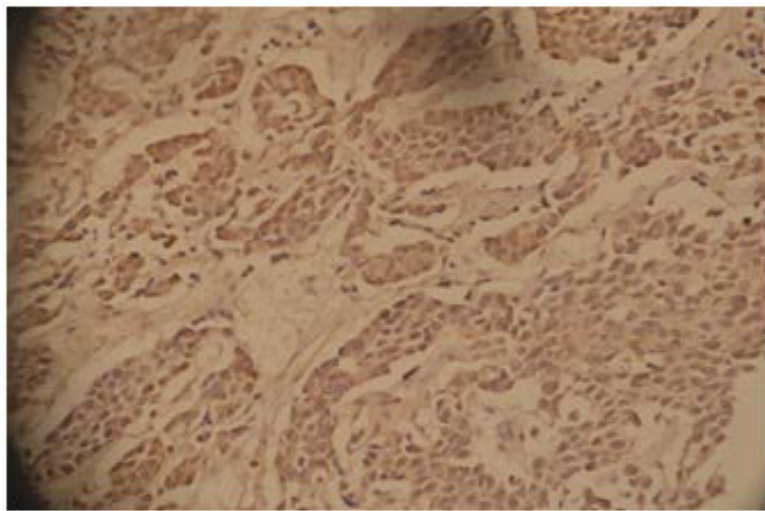

Figure 3: IHC showing positive staining with ACTH.

\section{Discussion}

Various benign and malignant tumors are associated with ectopic ACTH syndrome (EAS) includes small cell carcinoma of lung, carcinoid tumors (lungs, thymus, gastrointestinal tract), islet cell tumors, pheochromocytoma, medullary carcinoma thyroid (MTC), and various miscellaneous tumors like paragangliomas etc [4]. Amongst patients with ectopic Cushing syndrome (ECS), MTC represents 2.2$7.5 \%$ of the total cases; however MTC with clinical manifestation of ECS is rare and seen in $0.6 \%$ of patients, and has been described in sporadic and familial cases6. In our tertiary care center, out of 115 cases of MTC operated so far only one patient $(0.87 \%)$ presented with ectopic Cushing syndrome.

The definitive diagnostic criteria for EAS requires biochemical diagnosis of Cushing syndrome along with reversal of the clinical picture after resection of the tumour and/or demonstration of ACTH immunohistochemical staining in the tumor tissue or in metastatic deposits, and/ or complete/ partial resolution of the hypercortisolaemia after tumor removal/ debulking [8]. Our patient showed positive ACTH staining on thyroidectomy specimen along with complete resolution of hypercortisolaemia, confirming diagnosis of ectopic ACTH production.

Another important aspect is time gap between the onset of primary tumor and ECS. Most of these tumors acquire the ability to produce $\mathrm{ACTH} / \mathrm{CRH}$ at different stages of the disease. In our patient, duration between tumor and onset of Cushing symptom was six months; however,

Variable duration between onset of ECS and MTC has been reported, can be detected before or up to 20 years after MTC is diagnosed [9]. Barbosa et al, reported that among 1640 MTC patients, 13 developed EAS. Cushing syndrome revealed MTC in three cases and followed the diagnosis of MTC by an average of 34.5 months in the others [6].

Presence of ACTH staining on thyroid tissue was confirmatory of ectopic ACTH production like in our patient; however, failure to identify ACTH by immunostaining in the MTC and its metastases has also been reported [10]. That can possibly be due to aberrant processing of the proopiomelanocortin (POMC) molecule, leading to production of a biologically active form of ACTH which cannot be detected by current IHC techniques. So measuring POMC mRNA by in situ hybridization in these cases is very helpful in confirming the source of ectopic ACTH production [11].

Apart from primary tumor, untreated hypercortisolism alone can be fatal. If a single source of ectopic ACTH production has been located, the optimal management is surgical excision. There is a trend towards an increase in the proportion of patients cured of EAS: the 2001 Mayo Clinic series reported 12\% curative resection, while the 2005 series at the NIH achieved 29\% curative resections [12]. Other treatment options are tyrosin kinase inhibitors and inhibitors of cortisol production like ketoconazole and mitotane. In inoperable or metatstatic cases bilateral adrenalectomy can be considered as an option for control of hypercortisolism.

Prognosis of these patients depends on the index stage of primary tumor and adequacy of surgery, so patients with early tumor stage and curative surgery carry better prognosis. These patients need to follow up with basal or stimulated cortisol to assess the recovery of HPA axis along with serum calcitonin (tumour marker for MTC).

Unlike classical Cushing syndrome, in ectopic Cushing syndrome hyperpigmentation, weight loss, myopathy, and glucose intolerance are prominent symptoms. So careful examination and high index of suspicion is the key to diagnosis and appropriate treatment.

\section{Learning points}

- High index of suspicion is required to make diagnosis of Ectopic Cushing syndrome

- Surgical removal of ectopic source should be the aim if feasible

\section{References}

1. Prague JK, May S, Whitelaw BC (2013) Cushing's syndrome. BMJ 346: f945.

2. Newell-Price J, Bertagna X, Grossman AB, Nieman LK (2006) Cushing's syndrome. Lancet 367: 1605-1617.

3. Baylin SB, Mendelsohn G (1980) Ectopic (inappropriate) hormone production by tumors: mechanisms involved and the biological and clinical implications. Endocr Rev 1: 45-77.

4. Choi HS, Kim MJ, Moon CH, Yoon JH, Ku HR, et al. (2014) Medullary thyroid carcinoma with ectopic adrenocorticotropic hormone syndrome. Endocrinol Metab (Seoul) 29: 96-100.

5. Kebebew E, Ituarte PH, Siperstein AE, Duh QY, Clark OH (2000) Medullary thyroid carcinoma: clinical characteristics, treatment, prognostic factors, and a comparison of staging systems. Cancer 88: 1139-1148.

6. Laboureau-Soares Barbosa S, Rodien P, Leboulleux S (2005) Ectopic Adrenocorticotropic Hormone- Syndrome in Medullary Carcinoma of the Thyroid: A Retrospective Analysis and Review of the Literature. Thyroid 15 618-623. 
Citation: Bansal N, Saini S, Sabaretnam M, Mishra A (2015) Tale of Two Endocrine Organs: Medullary Thyroid Carcinoma (MTC) With Ectopic Cushing Syndrome. Surgery Curr Res 5: 217. doi:10.4172/2161-1076.1000217

7. Mehrotra PK, Mishra A, Mishra SK, Agarwal G, Agarwal A, et al. (2011) Medullary thyroid cancer: clinico-pathological profile and outcome in a tertiary care center in North India. World J Surg 35: 1273-1280.

8. Alexandraki KI, Grossman AB (2010) The ectopic ACTH syndrome. Rev Endocr Metab Disord 11: 117-126.

9. Chrisoulidou A, Pazaitou-Panayiotou K, Georgiou E, Boudina M, Kontogeorgos $\mathrm{G}$, et al. (2008) Ectopic Cushing's syndrome due to $\mathrm{CRH}$ secreting liver metastasis in a patient with medullary thyroid carcinoma. Hormones (Athens) 7: 259-262.
10. Howlett TA, Price J, Hale AC, Doniach I, Rees LH, et al. (1985) Pituitary ACTH dependent Cushing's syndrome due to ectopic production of a bombesin-like peptide by a medullary carcinoma of the thyroid. Clin Endocrinol 22: 91-101.

11. Sheikh-Ali M, Krishna M, Lloyd R, Smallridge RC (2007) Predicting the development of Cushing's syndrome in medullary thyroid cancer: utility of proopiomelanocortin messenger ribonucleic acid in situ hybridization. Thyroid 17: 631-634.

12. Isidori AM, Lenzi A (2007) Ectopic ACTH syndrome. Arq Bras Endocrino Metabol 51: 1217-1225. 